\title{
Pitching non-English language research: A dual-language application of the Pitching Research Framework
}

\author{
Robert Faff ${ }^{\mathrm{a}, 1}$, Xuefeng Shao ${ }^{\mathrm{b}}$, Faisal Alqahtani ${ }^{\mathrm{c}}$, Muhammad \\ Atif $^{\mathrm{d}}$, Anna Białek-Jaworska ${ }^{\mathrm{e}}$, Angel Chen ${ }^{\mathrm{a}}$, Geeta Duppati ${ }^{\mathrm{f}}$, \\ Marisol Escobar ${ }^{\mathrm{a}}$, Marinela Finta ${ }^{\mathrm{g}}$, Anne Jeny ${ }^{\mathrm{h}}$, Ya Li ${ }^{\mathrm{a}}$, Marcio \\ Machado $^{i}$, Takahiro Nishi ${ }^{j}$, Bao Nguyen ${ }^{\text {a }}$, Jae-Eun Noh ${ }^{a}$, Jurij- \\ Andrei Reicheneckerk ${ }^{\mathrm{k}}$, Hideaki Sakawal, Eleftheria Vaportzis ${ }^{\mathrm{m}}$, \\ Luluk Widyawati ${ }^{\mathrm{a}}$, Singgih Wijayana ${ }^{\mathrm{n}}$, Chinthake Wijesooriya ${ }^{\mathrm{a}}$, \\ George $\mathrm{Ye}^{\mathrm{a}}$ and Clara Zhou ${ }^{\mathrm{a}}$ \\ ${ }^{\mathrm{a}}$ University of Queensland, Australia; ${ }^{\mathrm{b}}$ University of New South Wales, \\ Australia; ${ }^{c}$ Taibah University in Saudi Arabia, Saudi Arabia; ${ }^{\mathrm{d}}$ Griffith \\ University, Australia; ${ }^{e}$ University of Warsaw, Poland; ${ }^{\mathrm{f}}$ University of \\ Waikato, New Zealand; ' Singapore Management University, Singapore; ${ }^{\mathrm{h}}$ \\ ESSEC Business School, France; ${ }^{i}$ University Federal University of Paraiba, \\ Brazil; ${ }^{\mathrm{j}}$ Meiji University, Japan; ${ }^{\mathrm{k}}$ University of Liechtenstein, Liechtenstein; \\ ${ }^{1}$ Nagoya City University, Japan; ${ }^{\mathrm{m}}$ Heriot-Watt University, Scotland; ${ }^{\mathrm{n}}$ \\ Gadjah Mada University, Indonesia
}

\begin{abstract}
The global language of scholarly research is English and so the obstacle of getting noticed is montainous when the article is not written in the English language. Indeed, despite rapid advances in technology, the "tyranny of language" creates a segmentation inhibiting scholarly research and innovation generally. Mass translation of non-English language articles is neither feasible nor desirable. Our paper proposes a strategy for remedying this segmentation - such that, the work of non-English language scholars become more discoverable. The core piece of this strategy is a "reverse-engineering" [RE] application of Faff's $(2015,2017 a)$ "pitching research" template. More specifically, we provide access to translated versions of the "cued" template across thirty-three different languages,
\end{abstract}

${ }^{1}$ Corresponding author: UQ Business School, University of Queensland, St Lucia. Qld. 4072. Australia. Email: r.faff@business.uq.edu.au; Telephone: +61 733468055 Fax: +61 733468166 
and most notably for this journal, including the Romanian and French languages. Further, we showcase an illustrative dual language French-English example.

Keywords: pitching research; template; discoverability; non-English language research; Arabic; Chinese; Dutch; French; Greek; Hindi; Indonesian; Japanese; Korean; Lao; Norwegian; Polish; Portuguese; Romanian; Russian; Sinhalese; Spanish; Tamil; Thai; Urdu; Vietnamese; Myanmar; German; Persian Bengali; Filipino; Italian; Afrikaans; Khmer (Cambodia); Danish; Finnish; Hebrew; Turkish

JEL classifications: G00; M00; B40; A20; B00; C00; D00; E00; F00; H00; I00; J00; L00; Q00; R00; Z00

\section{Introduction}

In this paper, we provide a multi-lingual "reverse-engineering" $[R E]$ application of Faff's $(2015,2017 \mathrm{a}, 2017 \mathrm{~b})$ "pitching research" template to make (the core essence of) non-English language scholarly publications more discoverable by the global research community. ${ }^{i}$ More specifically, we provide access to translated versions of the "cued" template across THIRTY-THREE different languages, namely: (1) Arabic; (2) Chinese; (3) Dutch; (4) French; (5) Greek; (6) Hindi; (7) Indonesian; (8) Japanese; (9) Korean; (10) Lao; (11) Norwegian; (12) Polish; (13) Portuguese; (14) Romanian; (15) Russian; (16) Sinhalese; (17) Spanish; (18) Tamil; (19) Thai; (20) Urdu; (21) Vietnamese; (22) Myanmar; (23) German; (24) Persian; (25) Bengali; (26) Filipino; (27) Italian; (28) Afrikaans; (29) Khmer (Cambodia); (30) Danish; (31) Finnish; (32) Hebrew; (33) Turkish. Further, we showcase an illustrative dual language example of the RE strategy for the French-English case, and provide access to counterpart dual language examples involving Chinese, Japanese and Vietnamese. These examples show how researchers can build a small, but effective, "bridge" from there mother toungue into English, thereby potentially opening up a pathway to being "discovered". We supplement these examples with reflective contributions from the exemplar pitchers, around the challenges, issues and value of this approach. In this exploratory way, we give a first view of a "soft" proof of concept that might encourage further extensions into some of the settings where the discoverability objective seems to be viably enhanced by our proposed "bridging" strategy.

Discoverability or visibility is a challenge that faces all researchers worldwide - with an ever increasing supply of good research entering the scholarly marketplace; this challenge is only becoming intensified. The global language of scholarly research is English and so the obstacle of getting noticed is magnified manyfold for an article that is not written in the English language. Indeed, despite rapid advances in technology, the "tyranny of language" creates a segmentation inhibiting scholarly research and innovation generally. 
The following is an extract of an email recently received by the first author and it serves as one anecdotal indicator of the potential language barrier facing non-English language speakers:

"Let me begin by thanking you for your simple template for pitching research. my name is ... I am a Ph.D. student in ... University... I have studied your interesting article titled "a template for pitching research". Because my mother tongue is ..., I am looking for a ... equivalent for the word "pitching". But I do not understand the exact meaning of this word in your article. This term has several meanings in English and the word "pitch" in your article can be interpreted with different meanings. For example, pitch in English means to throw something with a lot of force, often aiming carefully. I can liken the research to a ball in baseball. Initially, the researcher (i.e. the pitcher) throws it for her/his selected person as a guider (i.e. the pitchee). This throw should be in the way that the person's attention be attracted to the research (i,e. pitchee can receive the ball). The way to do that is your pitch template. Another meaning for "pitch" is to set a speech, examination or explanation etc at a particular level of difficulty. I can imagine starting a research as a conversation between two people at the $\mathrm{PhD}$ level that should be done properly and interpreting your pattern as a tool for doing this conversation..." [anonymous extract from an email received on 13/2/2018]

Ironically, this young scholar understood much more than she realised - as her insights into what the word "pitching" is meant to metaphorically convey are as close as one could possibly hope!

Mass translation of non-English language articles is neither feasible nor desirable. But is there some meaningful middle ground? We say yes! Indeed, our paper proposes a strategy for remedying this segmentation - such that non-English language scholars become more discoverable. ${ }^{\text {ii }}$ Within our team, several members take on the responsibility of creating the dual-language paired examples of worked template pitches: a first version in the "mother tongue", with a counterpart translated into English.

There are three basic steps in the process. Step 1 requires the pitcher to choose a relevant non-English language article that (ideally) should be recent, empirical and involve a research design which conforms to global industry norms relevant to the discipline in question. The academic journal should be: (a) one that publishes in the domestic (non-English) language only - though it is acceptable if an English language ("free form") abstract is published by the journal and (b) widely viewed as a very high quality journal (by domestic scholars). Ideally, the authors of the selected article are high profile/ "guru" scholars (at least, as viewed by the domestic academic community). The topic of the chosen article is something of particular interest to and in the area of expertise of the pitcher.

Step 2 then requires the pitcher to reverse engineer the article into the format of Faff's $(2015,2017$ a) pitching template. For example, in Step 2, a Chinese article is deconstructed into a Chinese language version of the template. This process will be broadly guided by the "parameters" enunciated by Faff - notably, including a 
1,000-word limit, minimum of needless repetition and an eye for flow and "connectivity". Step 3, then requires translating the domestic language template produced in Step 2, into an English language counterpart. The English language versions are polished, while maintaining reliable translation linkage with the original language version.

The current paper is organised as follows. ${ }^{\text {iii, iv }}$ Section 2 offers information on all thirty-three translated versions of the "cued" version of the pitching template. Section 3 provides a brief account from one of our authorship team, a native Chinese scholar, of first floating the idea of a Chinese version of the template tool. Section 4 discusses the Chinese language version of the template. Section 5 discusses the Spanish language version of the template, with a set of reflections by a Spanish team leader. Section 6 discusses the Vietnamese language version of the template. Section 7 discusses the Japanese and French language versions of the template and presents a worked paired example for French-English. Section 8 concludes.

\section{Translations of the "Cued" Template Tool and dual language exemplars}

Table 1 summarises the current state of development for creating translated versions of the "cued" template tool across many languages. In total, the table indicates that we have created translated versions of the main cued version of of Faff's (2015, 2017a) pitching template for 33 languages: (1) Arabic; (2) Chinese; (3) Dutch; (4) French; (5) Greek; (6) Hindi; (7) Indonesian; (8) Japanese; (9) Korean; (10) Lao; (11) Norwegian; (12) Polish; (13) Portuguese; (14) Romanian; (15) Russian; (16) Sinhalese; (17) Spanish; (18) Tamil; (19) Thai; (20) Urdu; (21) Vietnamese; (22) Myanmar; (23) German; (24) Persian; (25) Bengali; (26) Filipino; (27) Italian; (28) Afrikaans; (29) Khmer (Cambodia); (30) Danish; (31) Finnish; (32) Hebrew; (33) Turkish. All of these are currently available from the online e-library and Table 1 provides the specific hyperlinks for accessing them directly. ${ }^{\mathrm{V}}$ Table 2 presents the Romanian language case as a highly relevant example for the core readership of this journal. It is also available in the e-library, appendix A178, accessible using the hyperlink shown in Table 1.

Table 3 displays seven dual-language pitch examples that we have created, involving four non-English languages. Specifically, there are three Chines-English paired examples; one French-English paired example; two Japanese-English paired examples and one Vietnamese-English paired example. All of these are currently available from the online e-library and Table 3 provides the specific hyperlinks for accessing them directly.

\section{3. "Sowing the seeds" - why not a Chinese language Pitching Research Template?}

George Ye, one of the authorship team on the current paper, was a 2016 UQ Winter Research Scholar, exposed to many facets of the pitching research framework. ${ }^{\mathrm{vi}} \mathrm{In}$ this context, he generated an idea of translating the original English pitching template 
into the Chinese language, so that the university students in China can benefit from using the pitching template to develop their graduate thesis. George says that he experienced unforgettable hardship on writing the graduate essay in the final year of his bachelor degree because students in China hardly have any research experience during the previous three years of their study, and thus have limited knowledge on how to write an academic paper. Therefore, George put forward in Faff et al. (2016b) a belief that there is huge potential demand from university students in China for using this pitching template as guidance for their graduate thesis.

However, an English language version is not applicable in this setting. One reason is that not many university students can fully understand the English template and the content that should be put into each of the sections. Another reason is that even if students could comprehend the English template, they still need to translate into Chinese when writing their own graduate essay. This is because the Ministry of Education of the People's Republic of China requires the bachelor's graduate essay to be written in Chinese, except for those who major in other languages. George argues that a Chinese language pitching research template would be well received, as long as it can be adjusted to fit the requirement of the Chinese graduate essay.

The above view was drawn at the conclusion of George's experience as a Winter scholar, at the end of 2016. As such, it represents an important seed for the current paper. Indeed, it stands as an inspirational beginning to what we hope will grow into a rich fruit-bearing tree, empowering novice researchers to deliver real and meaningful advances in the stock of scholarly knowledge, irrespective of their mother tongue.

\section{Chinese tanguage template and paired worked examples}

\subsection{Potential users of the pitching template in China}

Jia (Angel) Chen, another member of our authorship team, was a 2017 UQ Summer Research Scholar. Jia, a Chinese national, was asked to continue developing the ideas of George Ye, as outlined in the previous section - with a specific focus on China. Jia stresses that currently, most Chinese scholars use their mother language, Chinese, to report their research. There are very few opportunities for them to write a research paper in English or present their ideas in English. There are three potential users of a Chinese-language version of the pitching research template: (a) undergraduate scholars; (b) postgraduate scholars and PhD students; (c) Chinese academic scholars.

Since most Chinese undergraduate scholars do not have much research experience, they are required to have the graduate thesis in the last year of university. The first step of their graduate thesis is an assessable paper called "thesis proposal", which is similar in spirit to Faff's $(2015,2017 \mathrm{a})$ pitching template. It seems that many Chinese universities do not provide a fixed format/template for the "thesis proposal", and so these students themselves might voluntarily choose to use the template design 
if they perceive it will help improve the quality of their proposal (and relatedly, improve their learning/understanding about research and ultimately their grades).

However, since China is well known for its complex procedures and proud traditions, it is easy to anticipate reasoning for not accepting the template. For example, they might think that the research outcomes would not be greatly affected because the "thesis proposal" is not viewed as being (directly) important, compared to the "graduate thesis" itself. Hence, it is critical to emphasize the value of generating clear and innovative ideas in graduates. Moreover, by arguing the strong link between these great ideas and higher quality graduate theses, (a) students would be more employable and (b) universities would enhance their academic reputation, thereby delivering expanded opportunities to connect and collaborate with overseas universities.

For Chinese postgraduate scholars, many supervisors require them to read mostly English literature. However, it is still common for postgraduate scholars to conduct research in Chinese. With Faff's $(2015,2017 \mathrm{a})$ template, they can learn how to understand a paper better. Moreover, for those postgraduates who would like to apply for a $\mathrm{PhD}$ program abroad, there could be a service develop to help them revise their proposals in the template format, to improve the quality, coherence and focus of their ideas. Compared with translation agents, such a service could be original and add significant value from a team of bilingual "professionals". This could easily reach a high level of efficiency, aided by the structured nature of the format.

For many Chinese academic scholars, while being very competent researchers, they are not adept at the English language. If a specialist team could help these Chinese scholars to distill their work into the template format and then translate into English, their signature research efforts could be known by many more scholars across the globe. Moreover, this enhanced "discoverability" could dramatically improve the chances of such Chinese scholars forming collaborations with international scholars. Conversely, a specialist team could potentially help translate English language templates of signature English based articles into a Chinese language version, catering for a potential market in China as well.

\subsection{Chinese-English dual language paired examples}

The cued version of the Chinese language pitching template is available in the elibrary, appendix A160, accessible using the hyperlink shown in Table 1. Angel, from our authorship team, created this version. Angel then followed a three phase approach to create a worked example for a dual-language pair of templates. Below is her personal account.

\section{Phase 1: Seeking the target paper}

My research interest is management accounting. Therefore I tried to search the top Chinese journal within this area online. And several journals popped up which are quite famous within the Chinese accounting academy. Through scanning the 
abstracts of different papers, I targeted one titled: "Internal control, inefficient investment, and enterprise value" at the top journal Friends of Accounting. It is one of the Chinese essential journals and the journal of the China commercial accounting institute. More importantly for me, the paper relates to internal control, which is the area I would like to conduct further research.

Phase 2: Reverse Engineered (RE) pitching in the Chinese language template I first translated each item in Faff's $(2015,2017 a)$ template into Chinese. I found it relatively easy to populate the content into each item because of my prior RE-pitch experience in the Summer Research Program at the University of Queensland. Nevertheless, I feel that every time I finish another RE-pitch template, I have a better understanding of the template itself and the paper that I read. It is not so much "practice makes perfect", but rather "practice makes better".

\section{Phase 3: Translation into an English language version}

During this process, I found it a bit challenging at first to translate some terms. Different languages have different writing styles, and I found it a little strange converting some terms/concepts into English. Based on my personal experience on these matters, I needed to "clear my mind" and so I tried reading some similar English literature first, forcing myself to revert back into the English language academic context. Having done this exercise for a while, armed with a greater familiarity of and confidence with the English related literature, I found the translation task much easier. Part of my strategy was to find similarities and differences between the writing style of the Chinese literature versus the English language counterparts. I would say it is definitely a good experience for me to have an appreciation of literature in my field, both in Chinese and English. Angel's Chinese-English language paired example is available in the e-library, appendix A232, accessible using the hyperlink shown in Table 3.

Another member of our authorship team, Clara, created a second Chinese worked example on "the game of fraudulent reporting". Her Chinese-English language paired example is available in the e-library, appendix A233, accessible using the hyperlink shown in Table 3. Also, Xuefeng, created a third Chinese worked example on "Strategic Management". His Chinese-English language paired example is available in the e-library, appendix A234, accessible using the hyperlink shown in Table 3.

\section{Spanish language pitching template}

Marisol Escobar, another member of our authorship team, was part of the 2016-17 UQ Summer Scholar Program. She believes that a Spanish language translated version of the pitching template could benefit Spanish-speaking university students during their research journey. This section considers the background scenarios of student researchers in Spanish speaking countries to determine the feasibility of this academic tool. There are 21 Spanish speaking countries across the world. ${ }^{\text {vi }}$ Hence, exploring each background scenario that research students might face in every one 
of these countries would be burdensome and pointless. In view of this, we break down these scenarios into three main categories/target groups.

Before continuing with the analysis, it's worth explaining some relevant Spanish academic terminology. When an undergraduate student completes all the requirements of their program they automatically obtain their bachelor's degree. However, there's a further step that students need to take to obtain their academic title. The main difference between both of these terms is that obtaining an academic title provides you the legal capacity to practice your profession. This means that if you obtain a bachelor's degree in Technical Industrial Engineering, for instance, for you to be able to legally sign projects, you would be required to have an academic title.

In some Spanish speaking countries, the only way to obtain the academic title is by developing a graduate thesis; however, in others, the student also has the option to produce a 'project report' or take a 'professional exam of sufficiency'. In either case, most universities don't have a 'structured program' (like honours for example) to engage students in research; it's something extra students are willing to do in order to obtain their title academic title.

Thus, the pitching template would help students to structure their research, efficiently assess the worthiness of their proposed project and pitch it to their supervisor. Furthermore, even though in some cases, there is no regulation that prevents graduates from Spanish university settings from writing their thesis in a language other than Spanish, it's very unlikely that they would follow this path since most feel far more comfortable writing such a piece of research in their native language. Hence, a Spanish translation of the original English template could benefit students in assisting them as a research planning tool. Considering this, the first category of potential users is undergraduate scholars who want to obtain an academic title by developing a graduate thesis. A second category are students who want to pursue postgraduate education (Masters/PhD) and they could use the translated pitch not only as a research planning tool but also as a research learning tool. Conducting different exercises with the pitch template would assist them in learning how to extract the core ideas from any piece of literature.

Finally, is there merit in the idea of translating the Spanish version back to the original English language template? One could argue that there is only limited motivation for undergraduate or postgraduate scholars in Spanish speaking universities to complete the pitching template in English, since they've already developed their thesis in Spanish. However, Marisol believes that by having the opportunity to upload their English language pitch to the PitchMyResearch.com web portal and be selected as 'Pitch of the week', scholars might be motivated to invest some time in translating their pitch into English. Moreover, since the global language of research is English, this could also be a motivation for those scholars who want to make their research more widely 'known' or visible across the international academic community. This would be particularly the case for those students "eyeing off" (research) careers outside of the Spanish speaking world. 
As a first step toward engaging with Spanish-speaking novice researchers, a Spanish language cued-version of Faff's $(2015,2017 \mathrm{a})$ pitching template is available in the e-library, appendix A161, accessible using the hyperlink shown in Table 1.

\section{Vietnamese language template and paired worked example}

The Vietnamese language translation of the cued template is available in the elibrary, appendix A176, accessible using the hyperlink shown in Table 1. Bao Nguyen is the member of our team charged with the responsibility of thinking about a Vietnamese language version of the pitching template. Bao followed a four-step process as follows, with the account below expressed in his words.

\section{Step1: Choosing a Vietnamese academic paper in the field of my interest}

Regarding step 1, finding a high-quality Vietnamese empirical study in the "financial institution" field of research was not as simple as I had first thought. Because Vietnamese papers are rarely shown in the results of academic search engines (such as Google Scholar), it is not feasible to do key-word searching to identify the paper of interest. Alternatively, I decided to shortlist prestigious Vietnamese journals in the financial area. Across these journals, I scanned for papers which are recently published and written by Vietnamese "gurus" in the field of research.

In the process of choosing the paper, I also realized that most academic papers in Vietnamese prestigious journals already had their abstract or summary part written in English. This fact suggests that Vietnamese researchers are aware of the importance of making their research more discoverable. However, these abstract/summary pieces are usually not specific enough to convey the key ideas/findings of their research to English language speakers.

\section{Step 2: Translating the Pitching Research Template into Vietnamese}

It is quite difficult to translate the title of each item of the template into Vietnamese, due to the fact that since they are carefully and extensively discussed in Faff (2015, 2017a), their meanings are much more nuanced than what the printed words literally convey. Consequently, although I tried to choose Vietnamese words that have similar meaning to each item's title, some translated cases do not fit perfectly.

\section{Step 3: Creating a worked example in the Vietnamese language}

Although the paper is written by Vietnamese gurus and published in a Vietnamese prestigious journal, it still has some drawbacks which challenged me in the process of filling the template. For example, the authors mentioned Caglayan \& Sak (2010) several times in their paper; therefore, I decided to choose it as one of three key papers. However, Caglayan \& Sak (2010) does not appear in the paper's reference list, so I lacked information to populate the template and had to find the information from an alternative source. 
Step 4: Translating the Vietnamese language template example into English Finally, the Vietnamese language version was translated into English. Bao's worked example pitch is on "capital structure". This Vietnamese-English language paired example is available in the e-library, appendix A235, accessible using the hyperlink shown in Table 3.

\section{Japanese and French language templates and paired worked examples}

\subsection{Japanese case}

The Japanese translation of the cued template is available in the e-library, appendix A162, accessible using the hyperlink shown in Table 1. Hideaki Sakawa created a paired bilingual worked example pitch on "Market Reaction to Management Forecasts and Actual Earnings Information". This Japanese-English language paired example is available in the e-library, appendix A236, accessible using the hyperlink shown in Table 3. Takahiro Nishi also created a paired bilingual worked example pitch - this one on determinants of life insurance demand in Japanese SMEs. This Japanese-English dual language paired example is available in the e-library, appendix A237, accessible using the hyperlink shown in Table 3.

\subsection{French case}

Table 4 shows the French translation of the cued template. Tables 5 and 6 provide Anne Jeny's paired bilingual worked example pitch on financial reporting - in French and English, respectively. This French-English language paired example is also available in the e-library, appendix A238, accessible using the hyperlink shown in Table 3.

\section{Conclusion}

Discoverability or visibility is a challenge that faces all researchers worldwide - with ever increasing supply of good research entering the scholarly marketplace; this "discoverability" challenge is only becoming intensified. The global language of scholarly research is English and so the obstacle of getting noticed is magnified manyfold when the article is not written in the English language. Our paper proposes a strategy for remedying this segmentation - such that non-English language scholars become more discoverable. The core piece of this strategy is a "reverse-engineering" [RE] application of the Faff"s $(2015,2017 \mathrm{a})$ "pitching research" template. More specifically, we provide access to translated versions of the "cued" template across THIRTY-THREE different languages. Further, we showcase an illustrative FrenchEnglish dual language example. In this exploratory way, we give a first view of a "soft" proof of concept that might encourage further extensions into some of the settings where the discoverability objective seems to be viably enhanced by our proposed strategy. 
Acknowledgments: The authors gratefully thank the following individuals for their translation assistance: Anouk Aleva, Mohan Balasubramaniam, Thanutchaporn Chirathammakun, Alvin Duong, Mahsa Esmaeilikia, Andrei Filip, Jaco Fourie, Maria Guidi, Eirik Hegland, Vesa Jakobsson, Carlo Jamandre, Anne Jeny, Ges Jørgensen, Jeppe Elkjær Jørgensen, Onder Kimyon, Anton Klarin, Yujie Lei, Neha Matlani, Vincent Masson, Ridwana Kabir Orchi, Chennai Pranita, Leeron Spitzer, Bala Subramanyam, Yunqi Zhang.

\section{References}

Ali, S. (2016) "Corporate governance and stock liquidity in Australia: A pitch", Accounting and Management Information Systems, 15(3): 624-631

Ali, S. (2017) "Women in the boardroom and their impact on default risk: A pitch", Accounting Research Journal, 30(2): 137-146

Ashraf, H. \& Manzoor, N. (2017) “An examination of customer loyalty and customer participation in the service recovery process in the Pakistani hotel industry: A pitch", Accounting and Management Information Systems, 16(1): 199-202

Atif, M. (2016) "CEO compensation and firm's cash holding: A pitch", Accounting and Management Information Systems, 15(3): 605-611

Beaumont, S. (2015) "An investigation of the short and long run relations between executive cash bonus payments and firm financial performance: A Pitch", Accounting and Finance, 55: 337-343

Brenner, M. (2016) "Investigating chef-leader behaviour impacts on subordinate work team identification: A pitch", Accounting and Management Information Systems, 15(4): 826-834

Clout, V. (2017) "Corporate boards, monitoring and securities class actions: A pitch", Accounting Research Journal, 30(3): 242-248

Dvoulety, O. (2017) "Determinants of Nordic entrepreneurship: A reverse engineered pitch", Accounting and Management Information Systems, 16(3): $420-426$

Ellis, P. (2016) "To find a standard format that measures the activities of a micro, small or medium business entity. A pitch", Accounting and Management Information Systems, 15(2): 420-427

Faff, R. (2015) “A simple template for pitching research", Accounting and Finance, 55: $311-336$

Faff, R. (2016a) "Mapping "pitching research" tasks into the RSD7 framework: A pedagogic perspective", available at SSRN: http://ssrn.com/abstract=2724451

Faff, R. (2016b) "The "pitching research" concept: 2015, a year in review", available at SSRN: http://ssrn.com/abstract=2721528

Faff, R. (2016c) "Learning from 'pitching research' competition winners: Insights and reflections", available at SSRN: https://ssrn.com/abstract=2891650

Faff, R. (2017a) "Pitching research ${ }^{\circledR}$ ", Version 15 (or beyond) available at SSRN: http://ssrn.com/abstract $=2462059$

Faff, R. (2017b), Pitching research ${ }^{\circledR}$ : A comprehensive resource center supplement, available at SSRN: https://ssrn.com/abstract=3018939 Faff, R. \& Kastelle, T. 
(2016) "Pitching research for engagement and impact", available at SSRN: http://ssrn.com/abstract=2813096

Faff, R., Godfrey, K. \& Teng, J. (2016a) "Pitching research evolution: An illustrative example on the topic of 'innovation and financial dependence"', available at SSRN: http://ssrn.com/abstract $=2776959$

Faff, R., Li, Y., Nguyen, B. \& Ye, Q. (2016b) "Pitching research: A pilot experiment with UQ Winter scholars", available at SSRN: http://ssrn.com/abstract= 2816233

Faff; R., Wallin, A., Brosnan, M., Carrillo, N., Darmawan, D., Dorris, A., Groen, M., Listiani, N., Maxwell, V., Orole, F., Pham, A., Salehudin, I., Simons, M., To, D., Tsoi, J., Wong, C., Woods, K., Yossa, N. \& Zhaunerchyk, K. (2016c) "Fantasy pitching II: Star Wars vs. Pokemon vs. R\&D vs. Uber", available at SSRN: http://ssrn.com/abstract=2827425

Faff, R., Ali, S., Atif, M., Brenner, M., Chowdhury, H., Crudas, L., Joubet, A., Malik, I., Nagar, V., Mi, L., Pullen, T., Siegrist, M., Smythe, S., Stephenson, J., Zhang, B. \& Zhang, K. (2017a) "Fantasy pitching", Accounting and Management Information Systems, 16(2), 360-379

Faff, R., Babakhani, N., Carrick, R., Chen, A., Dallest, K., Daunt, L., Escobar, M., Foley, G., Gill, C., Khong, M., Liu, M., Mahmud, D., McCullough, J., Ndugwa, N., Nguyen, B., O'Brien, S., Orole, F., Qureshi, A., Rad, H., Rekker, S., Shahzad, K., Smith, M., Tran Le Nghi, T., Tunny, W. \& Wallin, A. (2017b) "Motivating postgrad research students to pitch their ideas: What have we learned from 'pitching research' competitions at UQ?", available at SSRN: https://ssrn.com/abstract=2899942

Faff, R., Babakhani, N., Dallest, K., Daunt, L., Foley, G., O'Brien, S. \& Tran Le Nghi, T. (2017c) "Book of pitches: UQAPS 2016 pitching research competition final", available at SSRN: https://ssrn.com/abstract=2967736

Faff, R., Baladi, J., Buce, D., Du Plessis, G., Du Plessis, C., Dwyer, B., Honey, K., Melton, D., Oktaviani, F., Shen, S., Steele, L., Suhodo, D., Tanner, M., Unger, C., Wong, S., Xu, J. \& Zou, S. (2017d) "Fantasy Pitching IV: Batman, Donald Duck, Fast Food, Superpowers, Self-Determination”, available at SSRN: https://ssrn.com/abstract=2939489

Faff, R., Carrick, R., Chen, A., Escobar, M., Khong, M., Nguyen, B. \& Tunny, W. (2017e) "Pitching research: A reverse-engineer "Sparring" experiment with UQ Summer research scholars", Available at SSRN: https://ssrn.com /abstract=2903811

Faff, R., Carrick, R., Chen, A., Escobar, M., Khong, M., Nguyen, B. \& Tunny, W. (2017f) "Fantasy pitching III: UQ Summer research scholars - the role of "money" in the 21st Century", available at SSRN: https://ssrn.com/ abstract $=2906617$

Faff, R., Carrick, R., Chen, A., Escobar, M., Khong, M., Nguyen, B. \& Tunny, W. (2017g) "UQ Summer research scholar program: Insights and reflections from the pitching research "I-Templates" team", available at SSRN: https://ssrn.com/abstract $=2919027$

Faff, R., Gill, C., McCullough, J., Noh, J-E., Mahmud, S.N.D., Ndugwa, N., Eats, P. \& Ghorbani Gorji, S. (2017h) "Book of pitches: UQAPS 2015 pitching 
research competition final", available at SSRN: https://ssrn.com/ abstract $=2953842$

Faff, R., Lay, J. \& Smith, M. (2017i) "PoW! Using social media to leverage research visibility - "Pitch of the Week" posts in LinkedIn", available at SSRN: https://ssrn.com/abstract=2894069

Faff, R., Shao, X., Alqahtani, F., Atif, M., Białek-Jaworska, A., Chen, A., Duppati, G., Escobar, M., Finta, M., Li, Y., Machado, M., Nguyen, B., Noh, J-E., Sakawa, H., Vaportzis, E., Widyawati, L., Wijayana, S., Wijesooriya, C., Ye, Q. \& Zhou, Q. (2017j) "Increasing the discoverability of non-English language research papers: A reverse-engineering application of the pitching research template", available at SSRN: https://ssrn.com/abstract=2948707

Hale, R., Kilner, A., Nucifora, R., Plath C., Wu, E., Zhang, X. \& Faff, R. (2018) "Applications of 'Pitching Research': Insights and Reflections from the 2017 UQ Winter Research Scholars", available at SSRN: https://ssrn.com/ abstract $=3130029$

Iqbal, H. \& Ashraf, H. (2017) "Impact of behavioral factors towards the adoption of mobile learning among higher education students in public and private universities: A pitch", Accounting and Management Information Systems, 16(3): 406-412

Khong, M. \& Escobar, M. (2017) "New money: Are we ready to take on the impacts of a cashless society? A fantasy pitch", Accounting and Management Information Systems, 16(4): 641-647

Lee, G. \& Turner, M. (2017) "Do government administered financial rewards undermine firms' internal whistle-blowing systems? A pitch", Accounting Research Journal, 30(1): 6-11

Martinek, S. (2017) "The investment strategies of sovereign wealth funds: A reverse engineered pitch", Accounting and Management Information Systems, 16(4): 648-656

Maxwell, V. (2017) "Developing a research agenda through pitching", Accounting and Management Information Systems, 16(2): 380-395

McCredie, B. (2017) "Equity market consequences of the social media revolution", Accounting Research Journal, 30(2): 132-136

McKay, W. \& Haque, T. (2016) "A study of industry cost of equity in Australia using the Fama and French 5 Factor model and the Capital Asset Pricing Model (CAPM): A pitch", Accounting and Management Information Systems, 15(3): 618-623

Mugumya, E. (2017) "Firm characteristics, innovation, financial resilience under austerity and survival of firm: A pitch", Makerere Business Journal, 13: 179-186

Nguyen, B. \& Chen, J. (2017) "Gender impact of chasing dirty money policies: A fantasy pitch", Accounting and Management Information Systems, 16(4): 633-640

Nguyen, N. H. \& Truong, T.P. (2017) "Regulatory enforcement, financial reporting quality and investment efficiency: A pitch", Accounting Research Journal, 30(1): $12-18$ 
Nguyen, B., Faff, R. \& Haq, M. (2017) "Pitching research lite: A reverse-engineering strategy for finding a new research direction", available at SSRN: https://ssrn.com/abstract=2909549

Qureshi, A. (2016) "Conceptualizing Schwartz values in university preference decisions: A pitch", Accounting and Management Information Systems, 15(3): 612-617

Rad, H. (2016) "Pairs trading and market efficiency using an adaptive market hypothesis framework: A pitch", Accounting and Management Information Systems, 15(1): 178-185

Rahman, D. (2016) "Investor sentiment, executive compensation, and investment some international evidence: A Pitch", Accounting and Management Information Systems, 15(2): 428-433

Ratiu, B. (2016) "A reversed engineered pitch based on Rietveld (2016), "Creating value through the freemium business model: A consumer perspective", Accounting and Management Information Systems, 15(4): 810-818

Ratiu, R.V. (2015) "Financial reporting of European banks during the GFC: A pitch", Accounting and Finance, 55, 345-352

Rekker, S. (2016) "Converting planetary boundaries into action, a new approach to meeting global greenhouse gas targets: A pitch", Accounting and Management Information Systems, 15(1): 160-167

Salehudin, I. (2017) "Reverse engineering" the pitching research template: A simple tool to help understand the academic literature", Accounting and Management Information Systems, 16(1), 203-210

Shahzad, S.K. (2016) "Private firms' adaptation to climate change within the context of developing countries: A pitch", Accounting and Management Information Systems, 15(1): 168-177

Sinnewe, E. (2017) "Examining the economic consequences of concise integrated reports: A pitch", Accounting Research Journal, 30(4): 356-361

Sivathaasan, N. (2016) "Corporate governance and leverage in Australia: A pitch", Accounting and Management Information Systems, 15(4): 819-825

Teng, J. \& Faff, R. (2017) "A "snowballing" pedagogic strategy for pitching research: An illustrative example in finance", available at SSRN: https://ssrn.com/abstract=2906127

Unda, L. (2015) "Board of directors characteristics and credit union financial performance: A pitch", Accounting and Finance, 55: 353-360

Wallin, A. \& Spry, A. (2016) "The role of corporate versus product brand dominance in brand portfolio overlap: A Pitch", Accounting and Management Information Systems, 15(2): 434-439

Wong, C. (2017) "How did they make it? An examination of online personal branding: A pitch", Accounting and Management Information Systems, 16(3): 413-420

Xue, R. (2016) "Study of the contagion mechanism for opening risk of emerging equity markets in BRICS countries: A pitch", Accounting and Management Information Systems, 15(1): 154-159

Zhang, Y. (2017) "Client importance and audit quality, office level evidence from the banking industry: A pitch", Accounting Research Journal, 30(2): 147-152 
Table 1. Summary Listing of Alternative Language Translations of Cued Version of "Pitching Research" Template (and Hyperlinks)

\begin{tabular}{|c|c|c|}
\hline Language Translation & e-library Appendix \# & e-library Hyperlink \\
\hline Afrikaans & A188 & http://bit.ly/2vo34Nv \\
\hline Arabic & A168 & http://bit.ly/2pwl0nx \\
\hline Bengali & A185 & http://bit.ly/2vJOEIz \\
\hline Chinese & A160 & http://bit.ly/2qE5Rkg \\
\hline Danish & A190 & http://bit.ly/2vJM4Cb \\
\hline Dutch & A174 & http://bit.ly/2pJnScL \\
\hline French & A182 & http://bit.ly/2uqXYRF \\
\hline Filipino & A186 & http://bit.ly/2utOYLy \\
\hline Finnish & A191 & http://bit.ly/2hPdMHQ \\
\hline German & A180 & http://bit.ly/2uLKvPE \\
\hline Greek & A171 & http://bit.ly/2rdwKsn \\
\hline Hebrew & A192 & http://bit.ly/2wyqqhz \\
\hline Hindi & A166 & http://bit.ly/2pJReXC \\
\hline Indonesian & A169 & http://bit.ly/2pJIHF1 \\
\hline Italian & A187 & http://bit.ly/2wNkvVA \\
\hline Japanese & A162 & http://bit.ly/2rdBWg5 \\
\hline Khmer (Cambodia) & A189 & http://bit.ly/2voC4NP \\
\hline Korean & A170 & http://bit.ly/2pJXZZz \\
\hline Lao & A177 & http://bit.ly/2pRDx9v \\
\hline Myanmar & A179 & http://bit.ly/2hLgfTD \\
\hline Norwegian & A175 & http://bit.ly/2pwzHXY \\
\hline Persian & A184 & http://bit.ly/2vnWKW4 \\
\hline Polish & A164 & http://bit.ly/2qE6Cd6 \\
\hline Portuguese & A163 & http://bit.ly/2pJm5Vb \\
\hline Romanian & A178 & http://bit.ly/2uv8QK1 \\
\hline Russian & A165 & http://bit.ly/2pJQP8A \\
\hline Sinhalese & A183 & http://bit.ly/2vUfvBa \\
\hline Spanish & A161 & http://bit.ly/2pwsYNx \\
\hline Tamil & A172 & http://bit.ly/2rdVLE3 \\
\hline Thai & A173 & http://bit.ly/2qh1msY \\
\hline Turkish & A193 & http://bit.ly/2wN1Hpk \\
\hline Urdu & A167 & http://bit.ly/2pwfWQg \\
\hline Vietnamese & A176 & http://bit.ly/2rlwt6I \\
\hline
\end{tabular}


Pitching non-English language research:

A dual-language application of the Pitching Research Framework

Table 2. Summary Listing of Dual Language Pitch Examples (and Hyperlinks)

\begin{tabular}{ccc}
\hline Language Translation & e-library Appendix \# & e-library Hyperlink \\
\hline Chinese (1) & A232 & http://bit.ly/2tQJLxt \\
Chinese (2) & A233 & http://bit.ly/2DvKaVE \\
Chinese (3) & A234 & http://bit.ly/2HzalNB \\
French & A238 & http://bit.ly/2FVO1jX \\
Japanese (1) & A236 & http://bit.ly/2DuExHe \\
Japanese (2) & A237 & http://bit.ly/2HEIUlz \\
Vietnamese & A235 & http://bit.ly/2IruyWQ \\
\hline
\end{tabular}




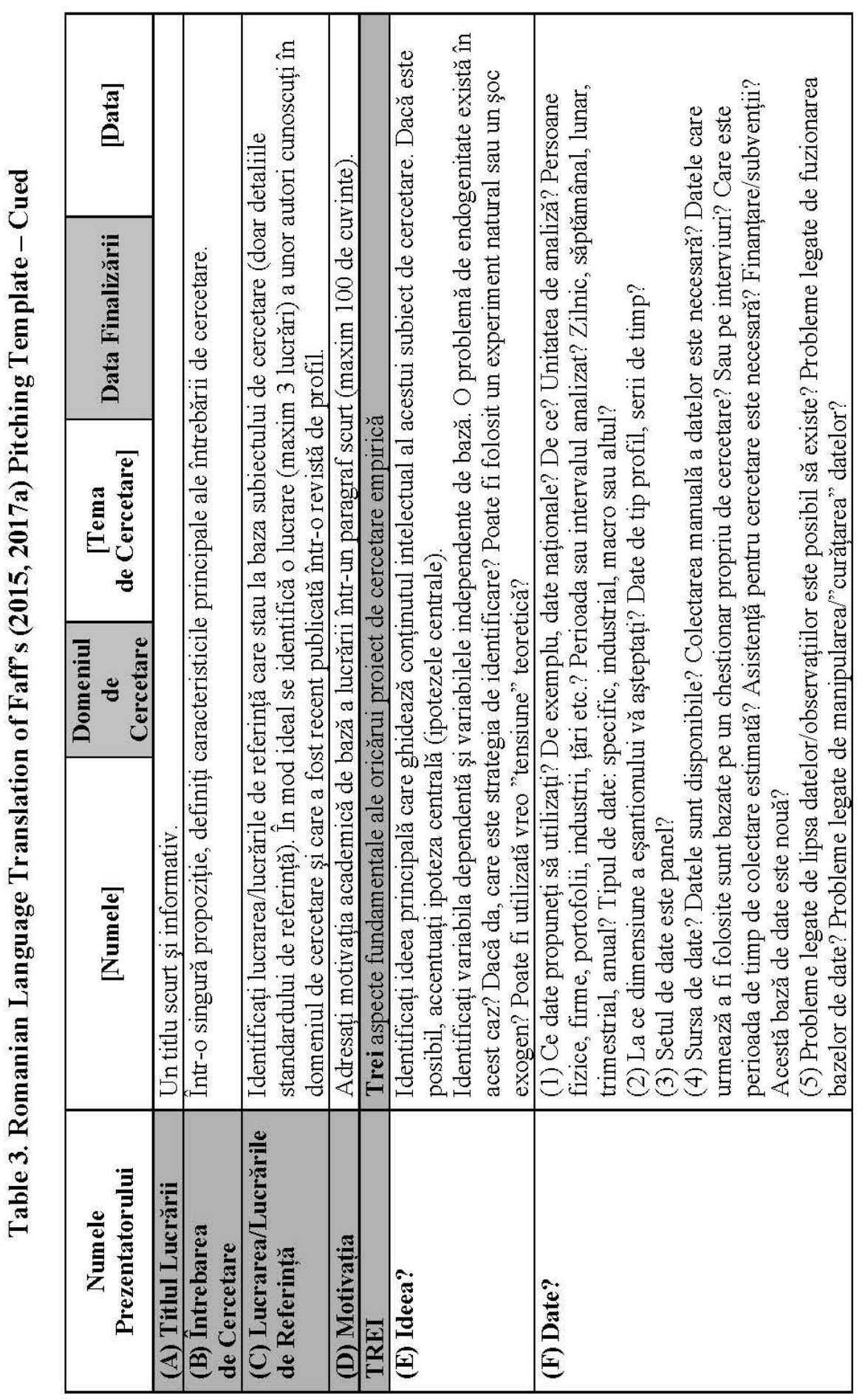


Pitching non-English language research:

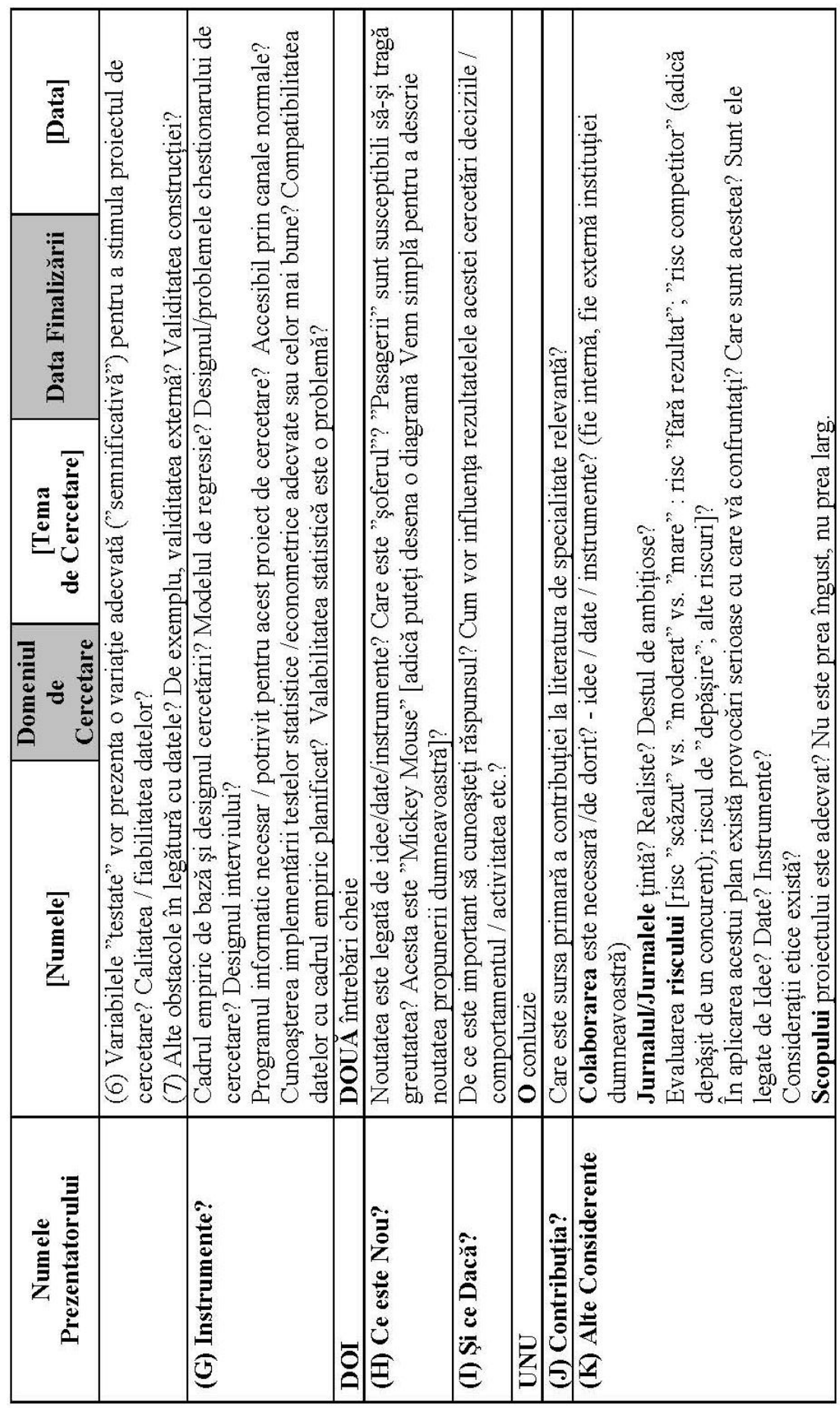




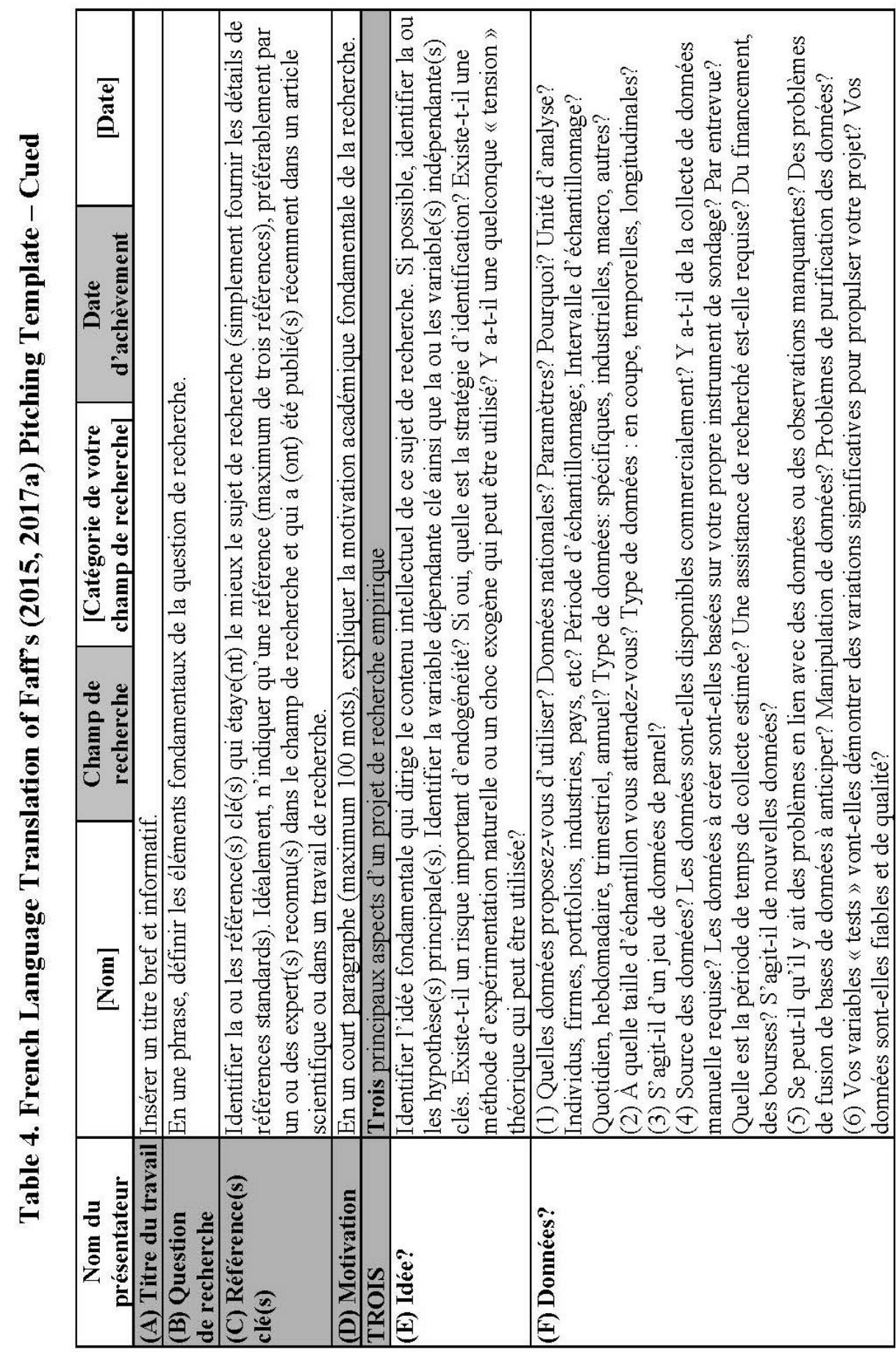


Pitching non-English language research:

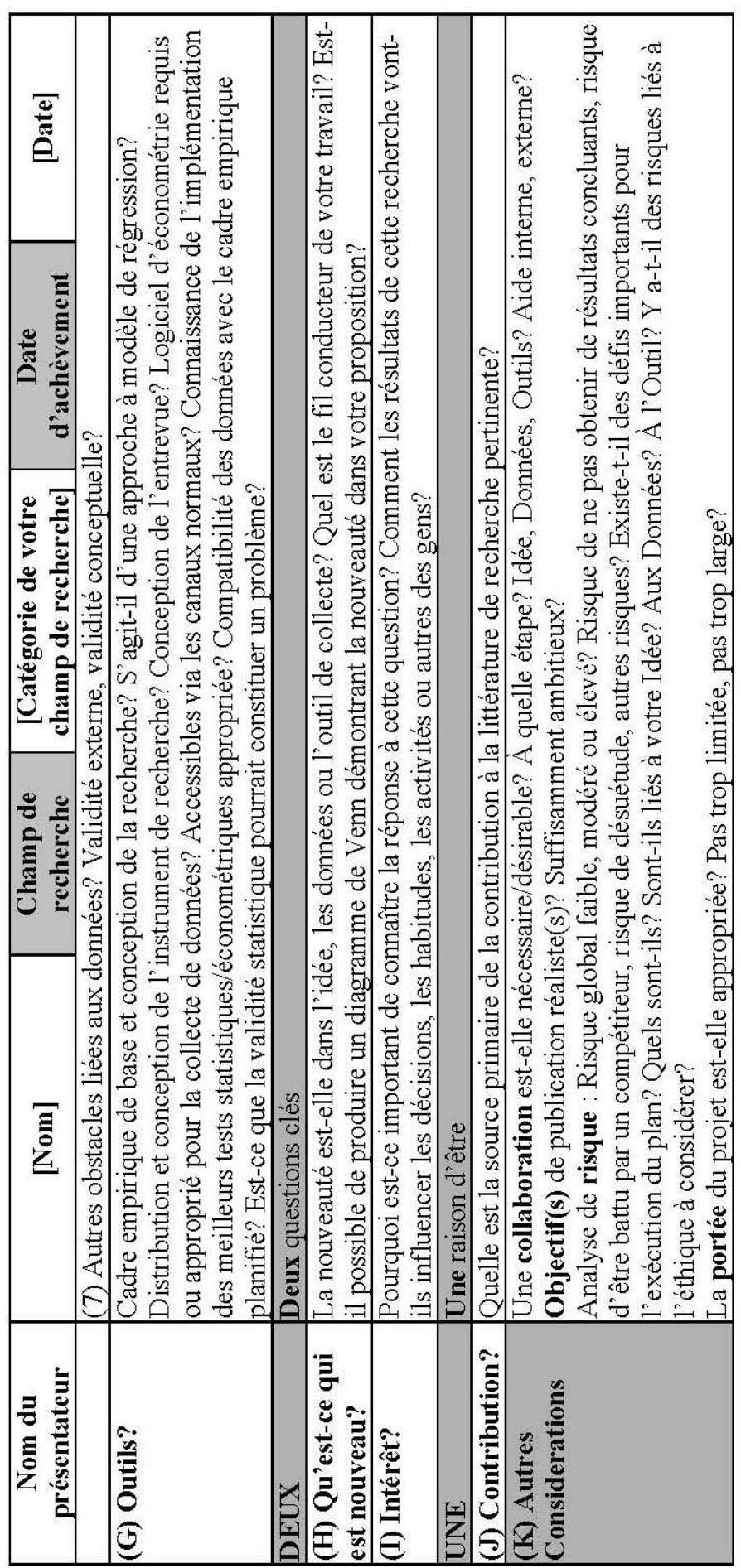




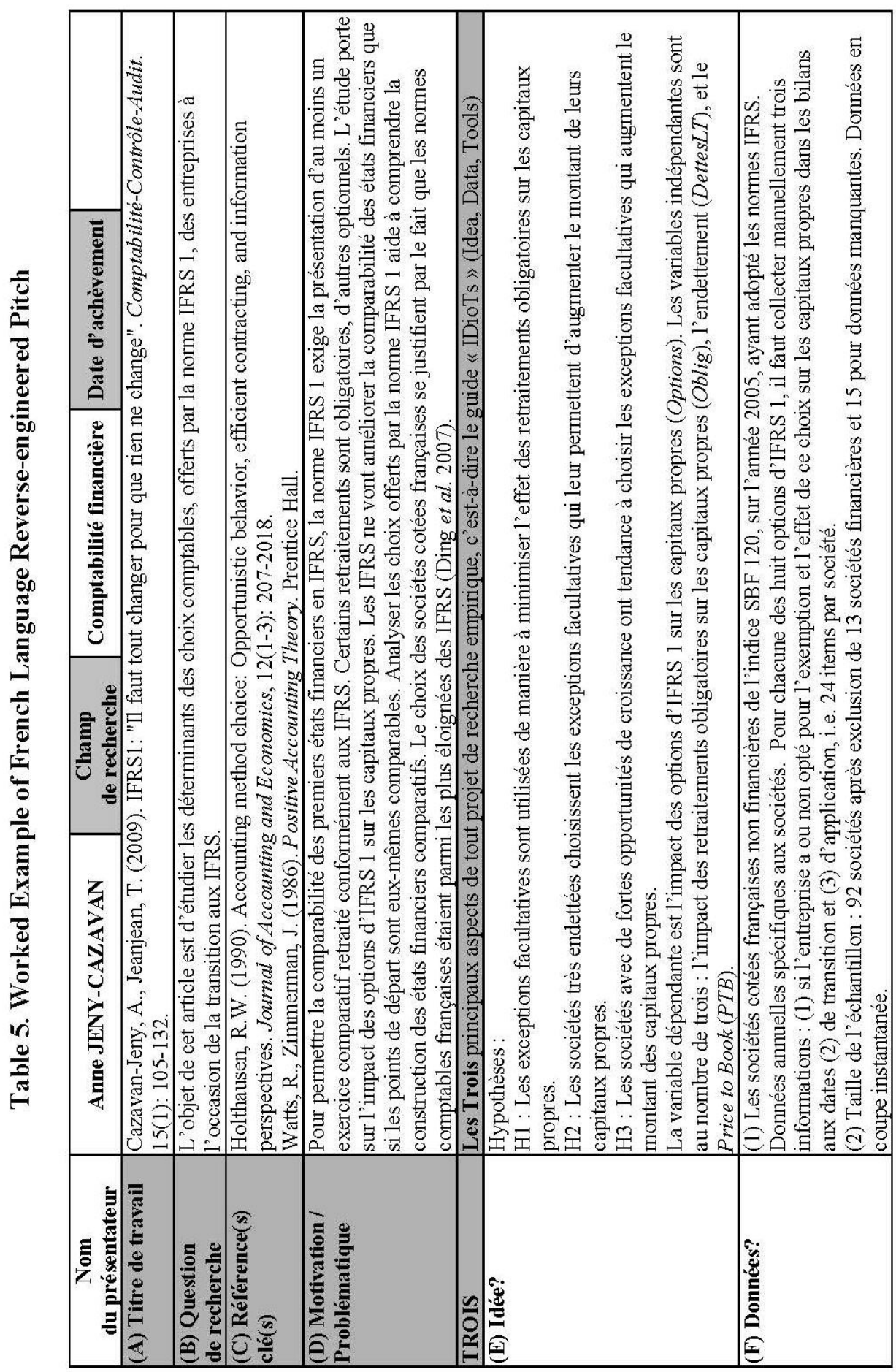


Pitching non-English language research:

A dual-language application of the Pitching Research Framework

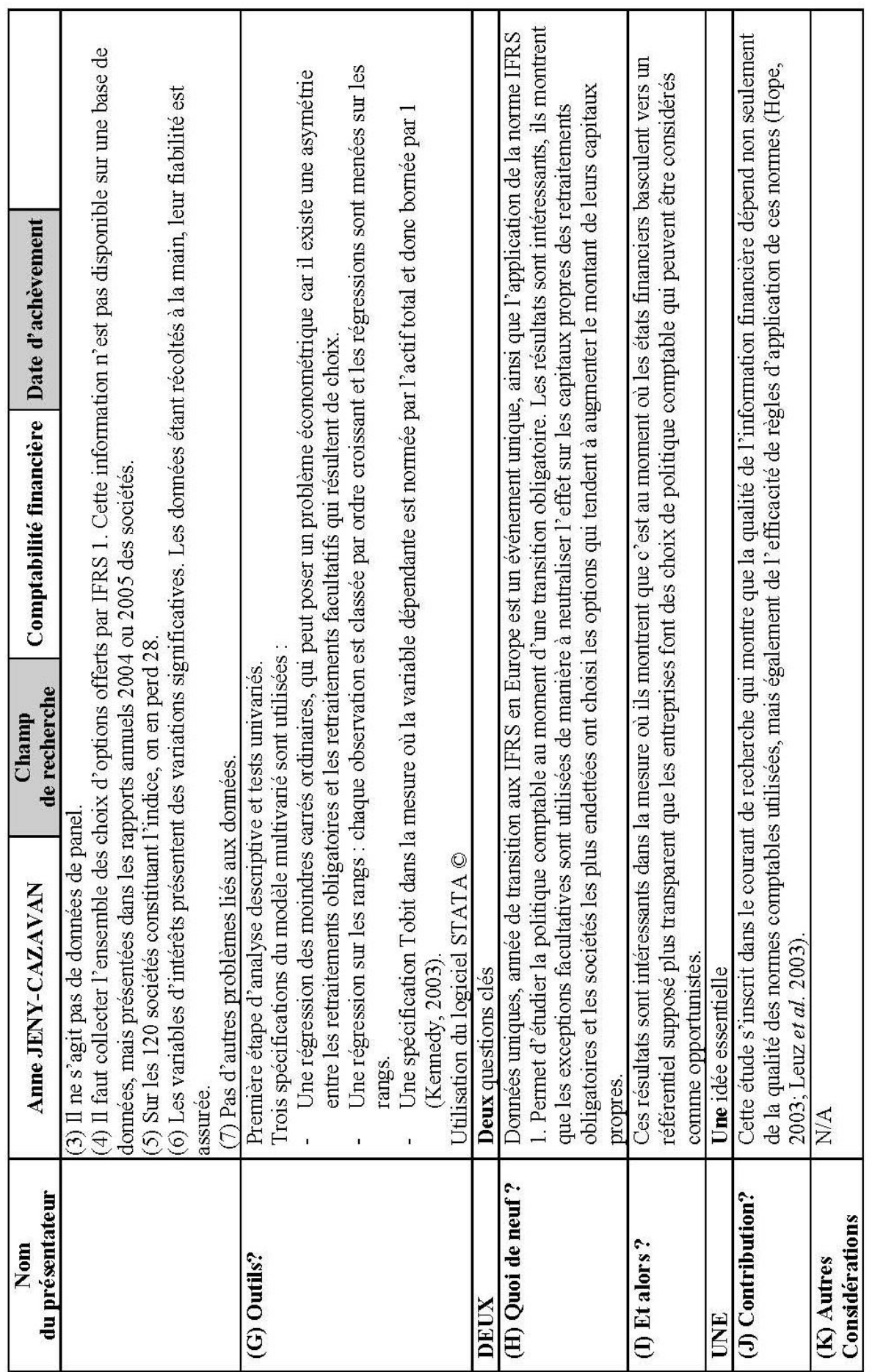

Vol. 17, No. 2 


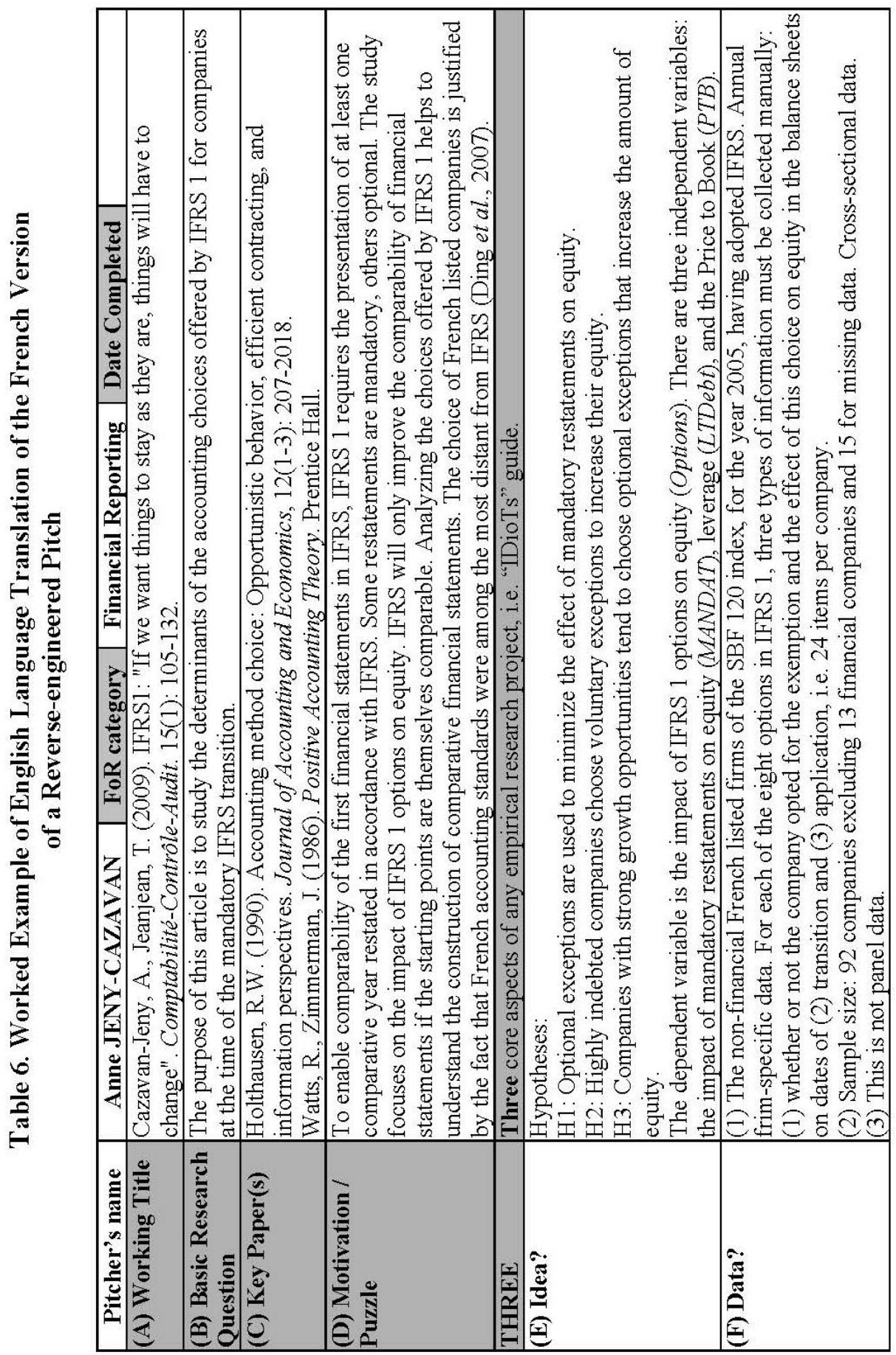


Pitching non-English language research:

A dual-language application of the Pitching Research Framework

\begin{tabular}{|c|c|c|c|c|c|c|c|}
\hline & 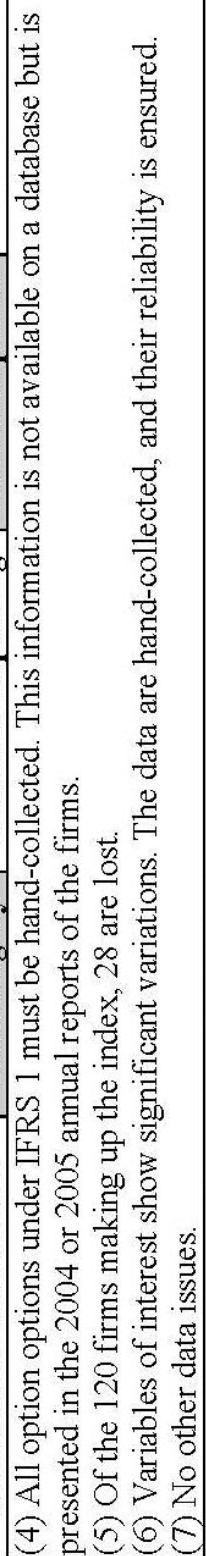 & 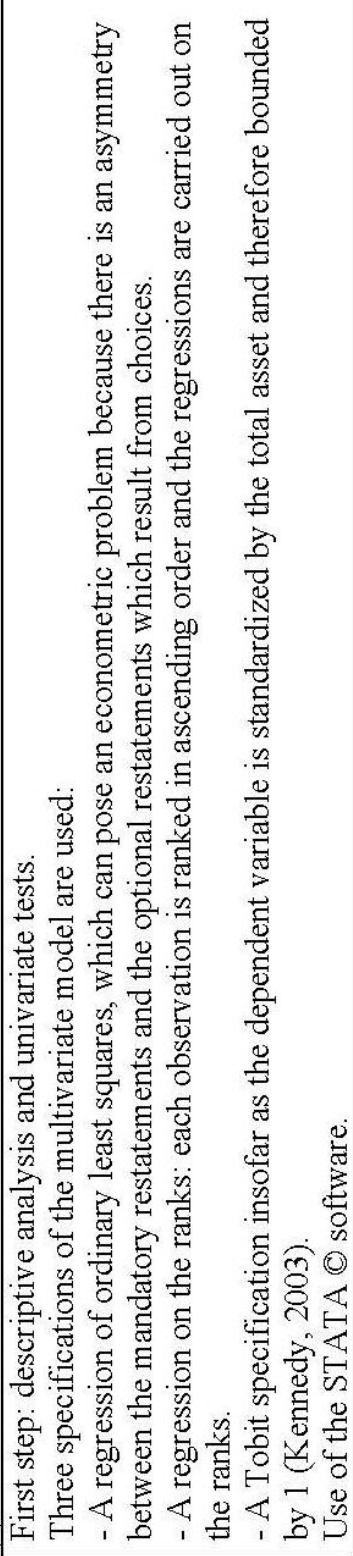 & 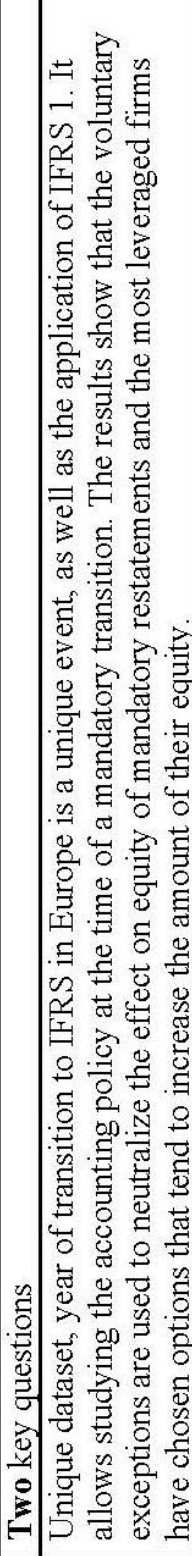 & 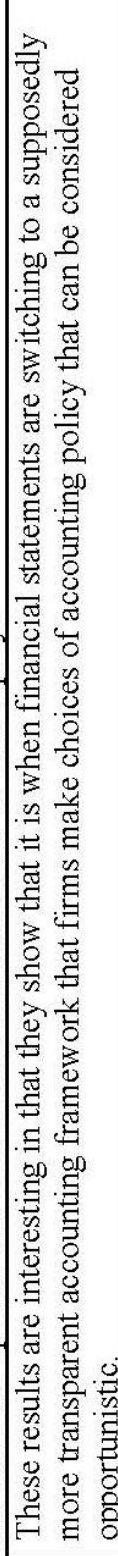 & & 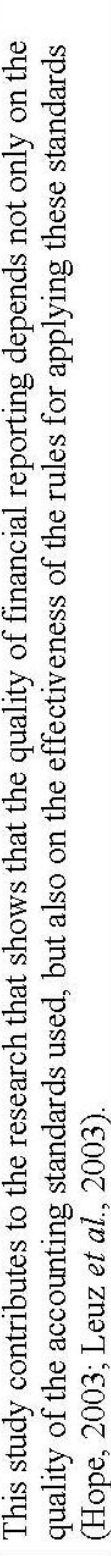 & \\
\hline & & (0) & 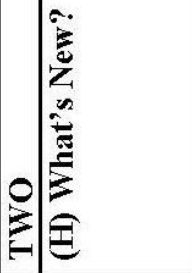 & $\stackrel{\xi}{\ominus}$ & & & 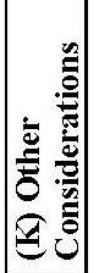 \\
\hline
\end{tabular}

Vol. 17, No. 2 
i The current article is companion to our 'discoverability' paper, Faff et al. (2017j) (SSRN ID 2948707). We recommend that you access Faff et al. (2017j) (SSRN ID 2948707) for the latest developments regarding the 'discoverability' initiative - this SSRN companion paper will be updated as needed e.g. with the advent of either new languages or with new dual-language pitch examples.

ii Consider the following local (Polish) perspective from one of our co-authors, Anna BiałekJaworska. Anna says: "This is a great idea and this really works. I cross my fingers that this will improve native (non-English) language research discoverability. Nowadays in Poland we can observe that more and more national journals invite papers in English and encourage authors to publish in English in accordance with internationalization strategy highlighted in the higher education reform. The government realized the need of scholarly publications of Polish scientists more discoverable by the global research community. However, it chose the simplest way of this - open access journals with new papers published in English (and sometimes even translated by the journal editorial staff). Unfortunately, this solution does not suit to good papers that have been already published in Polish. Therefore, Poland needs your tool to make earlier (previously published) nonEnglish (Polish) language scholarly publications more discoverable by the global research community. Both scholars (with previously published papers in their native (Polish) language) and students could benefit from your idea and use of the pitch template."

iii It is noteworthy that the current paper is part of a rapidly growing stable of PR papers. Faff (2015) and Faff (2017a) are at the core, with Faff $(2017 \mathrm{a} \& \mathrm{~b})$ representing the living "central clearinghouse" paper - providing updated information/weblinks to the growing set of "pitching" resources and initiatives. The broader program of "pitching research" papers comprise: Faff (2016a - 2016c); Faff (2017b - 2017j); Faff \& Kastelle (2016); Hale et al. (2018); Nguyen, Faff \& Haq (2017) and Teng \& Faff (2017).

iv An alternative angle on the pitching experience is captured by "pitching research letters" (PRLs) which provide case studies of the pitching process. PRL examples include: Ali (2016, 2017); Ashraf \& Manzoor (2017); Atif (2016); Beaumont (2015a,b); Brenner (2016); Clout (2017); Dvoulety (2017); Ellis (2016); Iqbal \& Ashraf (2017); Khong \& Escobar (2017); Martinek (2017); Maxwell (2017); MaCredie (2017); McKay \& Haque (2016); Mugumya (2017); Nguyen \& Chen (2017); Nguyen \& Truong (2017); Qureshi (2016); Rad (2016); Rahman (2016); Ratiu (2016); Ratiu (2015a, b); Rekker (2016); Shahzad (2016); Sivathaasan (2016); Unda (2015a, b); Wallan \& Spry (2016); Wong (2017) and Xue (2016).

${ }^{v}$ The online e-library can be found at: http://bit.ly/2iyonHK

${ }^{v i}$ As stated on the UQ Advantage Office website:

"In the knowledge-based global economy, in-demand skills include the ability to think and reason critically, develop innovative ideas, analyse data and clearly explain results. The UQ Advantage Office actively supports UQ's culture of innovation and entrepreneurialism, and coordinates a range of programs which enable undergraduate students to build these skills through early research experience.

Through the UQ Summer and Winter Research programs you may receive a scholarship to work alongside some of the University's most talented researchers during semester vacation. These programs are an ideal way for undergraduate (including honours) and coursework masters students to test drive research before enrolling in a research higher degree program."

vii Africa: Equatorial Guinea; Caribbean: Cuba, Dominican Republic, Puerto Rico; Central America: Costa Rica, El Salvador, Guatemala, Honduras, Mexico, Nicaragua, Panama; Europe: Spain; South America: Argentina, Bolivia, Chile, Colombia, Ecuador, Paraguay, Peru, Uruguay, Venezuela. 